dos como média e desvio padrão das guias de cor, organizadas por valor, e diferença entre guias e cor no sistema CIEL*a*b* $(\triangle \mathrm{E})$ após realização de uma profilaxia dentária profissional. Foram realizados testes $\mathrm{t}$ de Student e ANOVA e calculado o coeficiente de correlação intraclasse (CCI) conforme apropriado. A significância estatística foi estabelecida para $\mathrm{p}<0,05$.

Resultados: Verificou-se uma diminuição de valor médio de guia de cor nas duas escalas, após a realização da profilaxia profissional, para todos os operadores com valores entre 0,15 e 0,58 para a escala VITA Classical e 0,19 e 0,45 para a 3D-Master, embora sem diferenças estatísticas entre consultas, independentemente do método utilizado. As diferenças de cor detetadas no sistema CIEL ${ }^{*}{ }^{*} b^{*}(\Delta E)$ foram de 1,58 $\pm 1,28 ; 2,07 \pm 2,20$ e 2,80 $\pm 2,56$ para o SpectroShade, clínico e voluntário, respetivamente. Nenhuma das diferenças detetadas atingiu o limiar clinico de percetibilidade $(3,7)$ e não existiram diferenças significativas entre métodos. O CCI melhorou da primeira para a segunda consulta em $87 \%$ dos subgrupos analisados no sistema CIEL*a*b*, sugerindo que a realização de uma higiene oral profissional poderá melhorar a concordância entre métodos.

Conclusões: A profilaxia dentária profissional produziu alterações na cor dentária através de uma diminuição do valor de guia e melhorou a concordância entre os diferentes métodos. No entanto, considerando o sistema CIEL*a*b*, as alterações de cor detetadas encontraram-se abaixo do limiar de deteção clínico.

http://doi.org/10.24873/j.rpemd.2017.12.105

\section{\#081 Comparação de métodos visuais e espectrofotométricos de determinação de cor dentária}

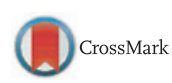

Rita Vanessa Alves *, Duarte Marques, Daniela Patrícia Cândido Corado, João Silveira, Ricardo Jorge Pinto, António Mata

GIBBO-LIBPhys FCT UID/FIS/04559/2013, Faculdade de Medicina Dentária da Universidade de Lisboa

Objetivos: O objetivo deste estudo in vivo foi avaliar a reprodutibilidade entre os métodos visuais e espectrofotométricos de determinação de cor dentária.

Materiais e métodos: Foi realizado um estudo de diagnóstico in vivo após aprovação da Comissão de Ética da Faculdade de Medicina Dentária da Universidade de Lisboa. Foram recrutados 30 pacientes e, de acordo com critérios previamente definidos, foram incluídos 20 após o seu consentimento esclarecido. Foram realizadas 1360 medições de cor dentária em incisivos centrais e caninos superiores em condições de iluminação padronizadas com o objetivo de avaliar a concordância intra- e inter-método para a determinação da cor por métodos visuais, com o auxílio das escalas de cor VITA Classical e VITA Tooth guide 3D-Master e, por métodos espectrofotométricos, com o Spectroshade micro e o VITA Easyshade. A reprodutibilidade foi avaliada através da concordância intra- e inter-método pelos Coeficientes Kappa \pm Erro Padrão Assintótico das guias de cor e pelo Coeficiente de Correlação Intraclasse com $95 \%$ de intervalo de confiança. Foram também realizados testes $t$ de Student e ANOVA para os valores de $\mathrm{L}^{*} \mathrm{a}^{*} \mathrm{~b}^{*}$ entre métodos conforme apropriado. A significância estatística foi estabelecida para $\mathrm{p}<0,05$.

Resultados: A concordância intra-método foi moderada a forte com coeficientes Kappa entre 0,65 $\pm 0,08$ e 0,81 $\pm 0,08$, à exceção do VITA Easyshade que apresentou uma concordância fraca com valores de 0,50 $\pm 0,06$ para a escala VITA Classical e de 0,53 $\pm 0,06$ para a VITA 3D-Master, respetivamente. Na avaliação da concordância inter-método foi possível constatar que os coeficientes de correlação intraclasse entre o Spectroshade micro e o método visual foram classificados como bons a excelentes com os valores a variar entre 0,81 e 0,94. No entanto, o VITA Easyshade e o método visual obtiveram valores de concordância inter-método reduzidos a moderados com valores de coeficiente de correlação intraclasse entre 0,38 e 0,65. Verificaram-se diferenças estatísticas nos valores médios $L^{*}$, $a^{*}$ e b* entre todos os métodos, à exceção do VITA Easyshade comparado com o método visual, no parâmetro $a^{*}$.

Conclusões: Os diferentes métodos testados in vivo para a determinação da cor dentária apresentaram diferentes níveis de reprodutibilidade. De acordo com os dados obtidos, os melhores valores de concordância foram verificados entre o método visual e o Spectroshade para a escala VITA Classical. http://doi.org/10.24873/j.rpemd.2017.12.106

\#082 Des-Remineralização de lesões de cárie induzidas artificialmente no esmalte

Q. Argi*, A.G. Manso, J. Carmo, A. Peixoto, P. Carvalho, C. Ascenso.

CiiEM - Centro de Investigação Interdisciplinar Egas Moniz, Quinta da Granja, Portugal, CeFEMA, Instituto Superior Técnico, Universidade de Lisboa and SINTEF Materials and Chemistry, Oslo

Objetivos: Análise microscópica da superfície do esmalte de 3 produtos de remineralização, após indução de um ciclo de desmineralização por cárie.

Materiais e métodos: 8 espécimes de esmalte humano ( $3 \times 4$ $\mathrm{mm}$ ), intactos e hígidos, foram selecionados e distribuídos aleatoriamente em 4 grupos: Grupo A-C ( $n=2$ em cada Grupo), submetidos com ácido láctico $(\mathrm{pH}=5)$, durante 6 dias, a $37^{\circ} \mathrm{C}$, simulando lesões artificiais de cárie dentária. Posteriormente foram escovados duas vezes ao dia, com escova elétrica e pasta dentífrica fluoretada (1450ppm de fluoreto de sódio), durante 7 dias; Grupo D $(n=2)$ corresponde ao grupo controlo - esmalte são. No Grupo B, foi aplicado uma única vez, no 7. ${ }^{\circ}$ dia, um verniz de flúor de alta concentração com fosfato de cálcio (<5\%), Clinpro ${ }^{\mathrm{TM}}$ White Varnish - 3M. No Grupo C, foi aplicada uma pasta de caseína fosfopeptidea fosfato de cálcio amorfo, 1 vez por dia, durante 7 dias, GC Tooth Mousse, Recaldent TM. Nos grupos A-C, durante os ciclos de escovagem os espécimenes estiveram submersos em água desionizada. Foi realizada uma análise qualitativa da superfície do esmalte através do microscópio eletrónico de varrimento, JEOL JSM-700001F, a x5000, x10000 e x30000.

Resultados: As imagens de microscopia eletrónica de varrimento revelam que os 3 grupos (A-C) apresentam alguma capacidade de preencher as lacunas prismáticas, existentes no esmalte, embora de forma distintas. O Grupo A revela pou- 